\title{
POLÍTICAS ADMINISTRATIVAS IMPERIAIS: O CASO DA OUVIDORIA DE PARANAGUÁ (1723-1812)
}

\author{
Jonas Wilson Pegoraro
}

Resumo: Este artigo apresenta a articulação entre as instituições político-administrativas do Império Ultramarino Português pontuando que inclusive as mais distantes instituições, no caso a Comarca de Paranaguá, estavam também inseridas na lógica governativa da Coroa. Por mais que as dinâmicas específicas da localidade provocassem diferentes ações políticas é certo que a Capitania de São Paulo e a Comarca de Paranaguá também participaram do gradual processo de centralização administrativa promovidos pela monarquia lusa.

Palavras-chave: Administração lusitana, Ouvidores régios, Comarca de Paranaguá

Abstract:This paper presents the relationship between the political and administrative institutions of the Portuguese Overseas Empire punctuating that even the most distant institutions, in case the 'Comarca

\footnotetext{
"Doutorando em História pela Universidade Federal do Paraná (UFPR). Mestre em História pela UFPR e Especialista em Literatura e História Nacional pela Universidade Tecnológica Federal do Paraná (UTFPR). Atualmente é professor assistente do Centro Universitário Curitiba (UNICURITIBA) e bolsista do Conselho Nacional de Desenvolvimento Científico e Tecnológico (CNPq).
} 
of Paranaguá, were also incorporated in the logic governing the Crown. As much as the specific dynamics of the locality provoke different policy actions is certain the 'Capitania' of São Paulo and the 'Comarca' of Paranaguá also participated in the gradual process of administrative centralization promoted by Lusitanian monarchy.

Keywords: Lusitanian Administration, Regal 'ouvidores', 'Comarca' of Paranaguá

Este artigo insere-se em uma discussão historiográfica que, atualmente, vem produzindo diversos estudos que objetivam uma melhor compreensão do que foi o império ultramarino português, procurando identificar os elementos que concorreram para a sua formação e como se pode, hoje, defini-lo. ${ }^{1}$ A historiografia veio retomar em toda a sua abrangência o clássico texto de Charles Boxer²,

${ }^{1}$ Dentre outros, pode-se citar: FRAGOSO, J.; BICALHO, M. F.; GOUVÊA, M. de F. (Org.). O antigo regime nos trópicos: a dinâmica imperial portuguesa (séculos XVIXVIII). Rio de Janeiro: Civilização Brasileira, 2001; ALENCASTRO, L. F. O trato dos viventes: formação do Brasil no Atlântico sul. São Paulo: Companhia das Letras, 2000; FURTADO, J. F. (Org.). Diálogos oceânicos: Minas Gerais e as novas abordagens para uma história do Império Ultramarino Português. Belo Horizonte: UFMG, 2001. BICALHO, M. F.; FERLINI, V. L. A. (Orgs.). Modos de governar: ideias e práticas políticas no império português - Séculos XVI-XIX. São Paulo: Alameda, 2005.

${ }^{2}$ BOXER, C. O império marítimo português 1415-1825. São Paulo: Companhia das Letras, 2002. - Originalmente lançado em 1969 sob o título: "The Portuguese seaborne empire: 1415-1825", teve em sua primeira tradução portuguesa, datada de 1977, momento que o título foi vertido para "O império colonial português". 
reivindicando, entretanto, uma melhor conceituação desse império ultramarino. Para tal, o contato entre as historiografias brasileira e portuguesa que se preocupam com uma mesma problemática mostrouse imprescindível. ${ }^{3}$

Tendo em vista o imenso "corpo" que constituiu o império ultramarino português, tanto os trabalhos mais específicos quanto os comparativos tornam-se imperativos para uma definição mais clara do que seria esse império, fruto dos descobrimentos e conquistas iniciados ainda no século $\mathrm{XV}$. O vasto território do império português chegou a ocupar, no século XVII, as seguintes regiões: na Europa, seu "original" território na Península Ibérica, reconquistado dos mouros no século XIII e as ilhas atlânticas de Madeira e Açores, descobertas no século XV; na América, ocupava áreas, hoje, correspondentes ao território do Brasil, descoberto/conquistado a partir de 1500; na África, além de feitorias ao longo de toda sua costa, na parte ocidental pertencia a seu território as ilhas de Cabo Verde e São Tomé e Príncipe, descobertas, respectivamente, em 1460 e 1470, e ainda regiões do reino do Congo e Angola. Já na parte oriental o império ultramarino português ocupava

\footnotetext{
${ }^{3}$ Indica-se, principalmente, a influência que veio a ter os estudos de Antonio Manuel Hespanha no campo acadêmico brasileiro na passagem do século XX para o XXI. Além dele, estudos de Nuno Monteiro, José Subtil e Mafalda Cunha também tiveram (e tem) repercussões em suas áreas afins.
} 
regiões de Moçambique; estendendo-se para a Ásia seu domínio ia de Ormuz, no Golfo Pérsico, até o Japão, passando por fortalezas na Índia, Macau, China, Ceilão, Insulíndia e Malaca.

O crescente diálogo entre a historiografia brasileira e portuguesa abriu novas possibilidades de desenvolver estudos em conjunto e comparativos para analisar as distintas dinâmicas e relações que envolveram os espaços do império, tanto entre a metrópole e suas colônias como estas entre si. Ademais, a historiografia, ao se dedicar a pensar o império como um todo, ou seja, conectando seus múltiplos pontos e dinâmicas, fez um paralelo entre as relações na América, África e Oriente, tendo a metrópole como centro irradiador de uma política administrativa.

Assim, a análise das diferentes formas de relacionamento entre esses múltiplos espaços e sua articulação fez com que os estudos recentes sobre o império constatassem que, mesmo diante de uma dimensão plural, existiram estratégias e meios de ações políticas para configurar uma centralização régia que se apoiava em flexíveis instituições jurídico-administrativas. ${ }^{4}$ Tal flexibilidade dos órgãos

${ }^{4}$ CUNHA, M. S. da. Governo e governantes do Império português do Atlântico (século XVII). In: BICALHO, M. F.; FERLINI, V. L. A. (Orgs.). Op. Cit.; GOUVÊA, M. de F. Conexões imperiais: oficiais régios no Brasil e Angola (c. 1680-1730). Ibid, pp. 179-197. PEGORARO, J. W. A justiça régia e as estratégias de controle da 84 
governativos eram característicos do Antigo Regime ${ }^{5}$ português, uma vez que frente as necessidades encontradas nos territórios do império, as jurisdições e/ou funções de um oficial poderiam ser ampliadas ou diminuídas. "O que hoje soa confusão de atribuições ou superposição de jurisdições é elemento constitutivo e característico do Estado europeu entre os séculos XV e XVIII, do período que, de modo talvez impreciso, se convencionou chamar de Antigo Regime". ${ }^{6}$

De fato, o esforço centralizador régio foi uma das características que marcaram o império ao longo do século XVIII. Além disso, a retração do poderio no Oriente, a descoberta de ouro nas Minas Gerais e, em particular, as políticas aplicadas pelo Estado português, são exemplos das profundas mudanças nas relações entre a administração central portuguesa com suas colônias.

população da "América portuguesa" (Séc. XVIII). Atas do I Congresso Internacional de História: Território, Culturas e Poder, Braga, Instituto de Ciências Sociais da Universidade do Minho, 5 a 7 de dezembro de 2005. Ouvidores régios em Paranaguá: uma discussão sobre a centralização jurídico-administrativa na América Portuguesa (1723-1812). Em: DORÉ, A: SANTOS, A.C. de A. (Orgs.) Temas setecentistas: governos e populações no Império Português. Curitiba: UFPRSCHLA/Fundação Araucária, 2008.

${ }^{5}$ A expressão Antigo Regime é utilizada nesta dissertação como um "conceito para designar a dinâmica das sociedades ocidentais entre os séculos XVI e XVIII". NEVES, G. P.; VAINFAS, R. Antigo Regime. Cf. VAINFAS, R. Dicionário do Brasil Colonial. São Paulo: Companhia das Letras, 2003. p. 43.

${ }^{6}$ SOUZA, L. de M. e. O sol e a sombra: política e administração na América portuguesa do século XVIII. São Paulo: Companhia das Letras, 2006. p. 48. 
A existência de um processo de centralização administrativa voltado à consolidação do poder régio apoiava-se em uma política de controle ministrada pela administração central do Estado português (Desembargo do Paço, Casa de Suplicação e Conselho Ultramarino), dos múltiplos territórios que compunham o império ultramarino.

Deflagrado na metrópole e estendido para os demais espaços do império, o processo centralizador político-administrativo tinha na utilização da justiça régia e na inserção de instituições e agentes régios as suas principais armas. É flagrante o grande fluxo de oficiais régios enviados para o ultramar. ${ }^{7}$ A inserção desses diversos agentes nos múltiplos espaços do império ultramarino, dentre eles o ouvidor de comarca, vinham no intuito de aplicar a lei, a justiça e assegurar no ultramar as prerrogativas do Estado português.

É evidente que a partir de sua constituição o Estado português promoveu a inclusão e o estabelecimento de mecanismos que proporcionassem um maior e eficaz controle sobre os territórios que estivessem sob seu domínio, disseminando sua lei e sua justiça. No caso da colônia luso-americana, estes mecanismos apareceram ainda no século XVI com o estabelecimento do Governo-Geral, em 1548, e

\footnotetext{
${ }^{7}$ Ver: CUNHA, M. Op. cit.; GOUVÊA, M. de F. Op. cit.; SUBTIL, J. Os Ministros do rei no poder local, ilhas e ultramar (1772-1826). Penélope, nº 27, 2002, pp. 37-58.
} 
ganharam força, nos domínios portugueses, a partir da Restauração (1640).

Deste modo, com o intuito de gerir a América portuguesa, o Estado português foi formando, gradualmente, uma estrutura jurídicoadministrativa e, conseqüentemente, estabelecendo novos espaços de poder na região. Tais espaços de poder foram plataformas para a retomada do controle efetivo na aplicação da justiça na colônia americana, previamente delegada aos donatários.

A existência de um centro diretivo de poder, esse situado em Lisboa, e de uma política administrativa partindo desse centro para as demais áreas do império ultramarino fez com que se constituísse uma hierarquia institucional. Assim, entende-se que a administração central (Desembargo do Paço, Casa de Suplicação e Conselho Ultramarino) exercia influências sobre as estruturas intermediárias e periféricas do Estado português. ${ }^{8}$

\footnotetext{
${ }^{8}$ O termo "Estado português" - de tão difícil definição - adotado neste estudo, faz referência a "um amálgama de funções em torno do rei", não existindo, deste modo, uma "divisão de poderes ou funções, ao estilo de Montesquieu". Ver: WEHLING, A. e WEHLING, M. J. Direito e justiça no Brasil colonial: o Tribunal da Relação do Rio de Janeiro (1751-1808). Rio de Janeiro: Renovar, 2004. p. 29. Além do mais, o Estado seria aquele que deveria promover a ordem social e o "bem-viver" em sociedade, responsável por ditar ao corpo social português as leis para o bem comum.
} 
O Estado português passou, essencialmente, a possuir ações diretivas de governo, formando uma rede hierárquica de instituições centrais, intermediárias e periféricas, com determinados cargos e funções próprios para a lógica administrativa do Antigo Regime. A formação de tal estrutura foi determinante para o estabelecimento e manutenção do poder régio em diversos espaços do império.

Devido à flexibilidade das instituições e dos agentes que promoviam a administração durante o Antigo Regime, podem ser analisadas como fluídas. Entretanto, no pensamento corporativo da época e amparado no direito natural, não se sobressaía o indivíduo, mas sim se buscava o bem comum. Desse modo, aparentes frágeis relações de hierarquização, de fato, estavam incorporadas à lógica administrativa da época. ${ }^{9}$

\footnotetext{
${ }^{9}$ Ver: HESPANHA, A. M. As Estruturas Políticas em Portugal na Época Moderna. In: TENGARRINHA, José (Org.). História de Portugal. 2. ed. São Paulo: UNESP, 2001. pp. 117-181. Não vem ao caso, aqui, retornar a clássica discussão historiográfica da eficácia da administração colonial entre Caio Prado Junior e Raymundo Faoro, contudo, faz-se uma ponderação. Há mais de vinte anos lançou-se um olhar para tal discussão como sendo, na verdade, os "dois lados da mesma moeda". Esse olhar, proporcionado por Laura de Mello e Souza, foi possível na medida em que a autora confrontou as interpretações de Faoro e Caio Prado com a prática administrativa da sociedade mineira setecentista. Dessa análise, Mello e Sousa observou que, "engolfada em contradições, a administração mineira apresentou um movimento pendular entre a sujeição extrema ao Estado [argumento de Faoro] e a autonomia [proposição de Caio Prado]". Ver: SOUZA, L. de M. Desclassificados do 
$\mathrm{Na}$ medida em que o poder régio ia avançando por sobre a colônia brasileira por meio da estrutura criada pelo Estado português, acabou por constituir "uma cadeia de poder e redes de hierarquia que se estendiam desde o reino, dinamizando ainda mais a progressiva ampliação dos interesses metropolitanos, ao mesmo tempo que estabelecia vínculos estratégicos com os vassalos no ultramar". ${ }^{10}$ Assim, na conjuntura administrativa portuguesa daquele período materializava-se o que Maria de Fátima Gouvêa veio a chamar de "economia política de privilégios". ${ }^{11}$

A formação de uma "economia política de privilégios" seria caracterizada "por valores e práticas tipicamente de Antigo Regime" e produto da "grande circulação de oficiais régios por diferentes postos governativos no ultramar português". ${ }^{12} \mathrm{O}$ trânsito de oficiais régios pelo império estruturava-se em relações clientelares ${ }^{13}$ e de parentesco,

Ouro: a pobreza mineira no século XVIII. Rio de Janeiro: Edições Graal, 2004. p. 139.

${ }^{10}$ GOUVÊA, M. de F. Poder político e administração na formação do complexo atlântico português (1645-1808). In: FRAGOSO, J.; BICALHO, M. F.; GOUVÊA, M. de F. (Org.). Op. cit., pp. 287-315, p. 288.

${ }^{11} I d$.

${ }^{12}$ Ver: GOUVÊA, M. de F. Conexões imperiais..., passim.

${ }^{13}$ Ver: XAVIER, Â. B. e HESPANHA, A. M. As redes clientelares. In: HESPANHA, A. M. (Coord.). História de Portugal..., pp. 339-349. 
configurando-se alianças políticas e estratégias governativas ditadas/nomeadas a partir da metrópole para o controle do ultramar.

Amparado juridicamente, o Estado português estruturou uma rede hierárquica de instituições, cargos e poderes pelo ultramar. Com isso, articulou-se um sistema para a administração e governo dos múltiplos espaços do império ultramarino português. Porém, uma vez que os territórios do império apresentavam diversas dinâmicas, o Estado luso adotou distintas estratégias administrativas de controle para tais espaços. ${ }^{14}$ Nessa linha, as

políticas imperiais devem ser assim consideradas como o resultado da ação conjugada daqueles oficiais [régios] no que concerne à produção de conhecimento acerca dos espaços por eles administrados - com as escolhas e estratégias encaminhadas pela Coroa diante das possibilidades políticas e materiais verificadas. ${ }^{15}$

Em Portugal, os oficiais régios especializado e a estrutura jurídico-administrativa foram, respectivamente, agentes e espaço utilizado pelo soberano para a propagação do seu poder político para as demais regiões do Império português. Além disso, essa estrutura era o espaço da "materialização" do poder político régio, uma vez que as

\footnotetext{
${ }^{14}$ Ver: HESPANHA, A. M.; SANTOS, M. C. Op. cit

${ }^{15}$ GOUVÊA, M. de F. S. Conexões imperiais..., p. 180.
} 
diversas instituições organizadas hierarquicamente pelo Estado português exerciam o poder que era "emanado" do rei. Assim, na perspectiva do Antigo Regime português, o poder está associado ao monarca, centro da espiral de poder que se constituía pelas redes governativas do império português. ${ }^{16}$ Por meio da aplicação da justiça ${ }^{17}$ e seu domínio sobre ela, o rei e seus oficiais fizeram prevalecer um estatuto no qual a sociedade colonial estava inserida.

De fato, antes de a organizar, o direito imagina a sociedade. Cria modelos mentais do homem e das coisas, dos vínculos sociais, das relações políticas e jurídicas. E, depois, paulatinamente, dá corpo institucional a este imaginário, criando também, para isso, os instrumentos conceituais adequados. Entidades como 'pessoas' e 'coisas', 'homem' e 'mulher', 'contrato', 'Estado', 'soberania', etc., não existiram antes de os juristas os terem imaginado, definido conceitualmente e traçado a

${ }^{16}$ GOUVÊA, Maria de Fátima, FRAZÃO, Gabriel Almeida \& SANTOS, Marília Nogueira dos. "Redes de Poder e Conhecimento na Governação do Império Português, 1688-1735". Em: TOPOI, Revista de História do Programa de Pós-graduação em História Social da UFRJ v. 5. (8). jun 2004. 2004.

${ }^{17}$ Observa-se na justiça não "apenas uma das atividades do poder. Ela era - enquanto se manteve pura e sua imagem tradicional - a primeira, se não a única, atividade do poder". HESPANHA, A. M. Justiça e administração entre o Antigo Regime e a Revolução. Em: Justiça e litigiosidade: história e prospectiva. Lisboa: Fundação Calouste Gulbenkian, 1993, p. 385. 
suas consequências dogmáticas. Neste sentido, o direito cria a própria realidade com que opera. ${ }^{18}$

Para encaminhar a discussão das políticas administrativas imperiais foi trabalhado um com recorte bastante específico, a ouvidoria de Paranaguá e as ações de seus ouvidores no período compreendido de 1723 a 1812, sendo que, em especial, devido ao acesso documental, foca-se a análise nas vilas de Paranaguá e Curitiba.

\section{A Ouvidoria de Paranaguá}

A ouvidoria de Paranaguá foi criada em 1723, com a divisão da capitania de São Paulo em duas comarcas. Poucos anos antes, em 1709, o Estado português havia criado a capitania de São Paulo e Minas do Ouro, após retomar a posse da capitania de São Vicente dos herdeiros dos primeiros donatários Martim Afonso de Souza e Pero Lopes de Souza (capitanias de Sant'Ana e Santo Amaro). A ouvidoria de São Paulo, por sua vez, já existia desde 1699 e seu primeiro ouvidor, Antonio Luiz Peleja, nomeado pelo rei recebeu um regimento pelo qual devia governar as suas ações.

18 HESPANHA, Antonio Manuel. Cultura Jurídica Européia. Síntese de um
milénio. $3^{\text {a }}$ Ed. Mira-Sintra: Europa-América, 2003. p. 72 . 92 
A criação da capitania régia de São Paulo veio na esteira desse movimento de fortalecimento do poder régio nos meridianos da América portuguesa. Poucos anos antes de sua criação, em 1700, o governador-geral do Brasil, João de Lencastre, havia indicado à administração central em Lisboa sua preocupação

com a ausência de defesas militares em São Paulo, lembrava que a região fora recentemente transformada no principal cenário de exploração aurífera no Brasil, situação que adquiria maior gravidade em face dos conflitos suscitados pela sucessão espanhola na Europa. Temia ele que a presença diminuta da autoridade régia no sertão tornasse inútil todo aquele ouro para Portugal, nos mesmos moldes que a prata americana assim o fora para a Espanha. Além disso, ali se situava redes mercantis que sistematicamente organizavam expedições predadoras de índios que escapavam ao controle metropolitano. ${ }^{19}$

Observa-se, assim, que na passagem do século XVII para o XVIII, ocorreu uma mudança no foco da política administrativa lusitana para os territórios na América, que, conforme a historiografia, pode ser estendida a todo o Atlântico sul. ${ }^{20}$ Nesta perspectiva, no início do

${ }^{19}$ GOUVÊA, M. de F. S. Conexões imperiais..., p. 190.

${ }^{20}$ Veja-se que Angola recebeu seu primeiro ouvidor em 1696. Cf. SUBTIL, J. e SOARES, M. G. "Ouvidores e ouvidorias no Império Português do Atlântico", Actas do Congresso Internacional $O$ Espaço Atlântico de Antigo Regime: Poderes e Sociedades, Lisboa, Faculdade de Ciências Sociais e Humanas da Universidade Nova de Lisboa, 2 a 5 de novembro de 2005. Ainda ver, dentre outros: BOXER, C. R. A 
setecentos as políticas administrativas irradiadas a partir de Lisboa, no intuito de assegurar as prerrogativas e o fortalecimento régio, foram direcionadas para as áreas mineradoras e para o tráfico de escravos africanos, políticas que visavam um melhor controle dessas dinâmicas mercantis mais rentáveis para os cofres régios.

A capitania régia de São Paulo estava incluída nesta nova política administrativa do Estado português e, durante 1709 e 1748, a capitania possuía importantes zonas auríferas em seu interior. Porém, tendo em vista a necessidade de promover um maior controle administrativo das áreas mineradoras nas regiões das Minas, dos Goiases e do Cuiabá houve um desmembramento da capitania. Assim, em 1720, foi criada a capitania de Minas Gerais; depois, em 1748, foram criadas as capitanias de Goiás e de Mato Grosso. Este ano também foi momento em que a Capitania régia de São Paulo passou a ser subordinada ao governo do Rio de Janeiro. ${ }^{21}$ No que diz respeito aos

idade de ouro do Brasil. Dores de crescimento de uma sociedade colonial. São Paulo: Nacional, 1963.

O império marítimo português... BICALHO, M. F.; FERLINI, V. L. A. (Orgs.). Op. cit. FRAGOSO, J.; BICALHO, M. F.; GOUVÊA, M. de F. (Org.). Op. cit. ALENCASTRO, L. F. Op. cit.; FURTADO, J. F. (Org.) Diálogos oceânicos... SOUZA, L. de M. e. Op. cit. 2006.

21 "Paralelamente a esta divisão na administração civil, em 1745, foram criados os bispados de São Paulo e de Mariana (Minas Gerais), além das prelazias de Goiás e de Mato Grosso. De certa maneira, esta divisão eclesiástica também funcionava como uma estratégia para o estabelecimento do domínio português frente à Espanha, na 
territórios ao sul de São Paulo, em 1737, foi criado o território do Rio Grande de São Pedro e, em 1738, foi instalado o governo da Ilhas de Santa Catarina, ambos dependentes do governo do Rio de Janeiro. Esse desdobramento de estruturas administrativas no sul da América portuguesa pode ser, então, entendido como uma ação do Estado português em busca de um controle mais efetivo da região.

Conforme Arthur Lacerda, em março de 1698, a câmara da vila de São Paulo pleiteou junto ao rei o estabelecimento de quatro ouvidorias na região. Essas ouvidorias, por conveniência dos moradores, deveriam ser instaladas nas vilas de Itu, São Paulo, Paranaguá e uma que atendesse as vilas de Mogi, Paraíba, Taubaté e Guaratinguetá. Para o pagamento dos oficiais que fossem nomeados, as câmaras da região lançariam um tributo sobre as bebidas de aguardente da terra e vinhos. ${ }^{22}$ O pleito foi atendido apenas parcialmente. Em 1699, com a nomeação do ouvidor Antonio Luiz Peleja, foi criada a ouvidoria de São Paulo. Esse oficial, em maio de 1700, reuniu-se no Rio de Janeiro com Artur Sá de Meneses, governador e capitão-general do Rio

região". SANTOS, A. C. de A. Para viverem juntos em povoações bem estabelecidas: um estudo sobre a política urbanística pombalina. Curitiba, 1999. Tese (Doutorado em História). Universidade Federal do Paraná, p. 87.

${ }^{22}$ LACERDA, Arthur. As ouvidorias do Brasil colônia. Curitiba: Juruá, 2000. p. 3334. 
de Janeiro e demais capitanias do sul, e José Vaz Pinto, ouvidor do Rio de Janeiro, para que o governador, com o objetivo de "evitar alguma confusão", declarasse as vilas que se uniriam à nova ouvidoria de São Paulo e as que permaneceriam com a ouvidoria do Rio de Janeiro. ${ }^{23}$

Já naquela época, as vilas identificadas como pertencentes à ouvidoria de São Paulo mostram uma grande área geográfica postas sob a administração de seu ouvidor. Além do mais, no documento não há menção à vila de Curitiba, criada em 1693. Esta fazia parte da vasta jurisdição do ouvidor de São Paulo. Também foram incorporadas ao termo daquela ouvidoria as vilas de Pindamonhangaba, criada em 1705, e a de Laguna, criada em 1714.

Concomitante ao pleito camarário, o governo-geral do Estado do Brasil já vinha se preocupando com as porções meridionais do território. Como já indicado, o governador-geral do Brasil Dom João de Lancastre em correspondência enviada a administração central, em 1700, havia indicado sua preocupação com o território meridional, principalmente com as defesas militares e a diminuta autoridade regia

\footnotetext{
${ }^{23}$ Termo que fizerão entre Sy os ouvidores gerais o primeiro que foi desta ouvidoria, e o Ouvidorgeral que no tempo hera em o Ryo de Janeiro em o qual se declarou as Vilas pertencentes a esta ouvidoria. Revista do Arquivo Municipal de São Paulo (RAMSP). Ano I, vol. I, 1934. pp. 49-50. p.50.
} 
na região de São Paulo, local de exploração aurífera no Brasil. ${ }^{24}$ Assim, frente ao novo contexto minerador no Estado do Brasil, para uma melhor administração régia das terras coloniais no sul, foi criada em 1709 a Capitania régia de São Paulo e Minas do Ouro. ${ }^{25}$

Com o intuito de demonstrar sua autoridade e seu espaço de atuação, uma das primeiras ações do ouvidor Antonio Luís Peleja foi obter um indulto para os moradores acusados de crimes ocorridos até o momento antecedente à sua nomeação. A obtenção dessa graça real demonstrava que as justiças d’El Rei seriam, dali para frente, fielmente observadas por ele e por todos os moradores que estivessem sob sua jurisdição. $^{26}$

A concessão do perdão significava, primeiro, que o Estado português reservava a administração da justiça ao seu ouvidor recémnomeado e, segundo, proporcionava um estreitamento do relacionamento entre rei e vassalos, já que criava um novo espaço de negociação dos conflitos sociais, agora administrado pela própria

\footnotetext{
${ }^{24}$ Ver: GOUVÊA, M. de F. S. Conexões imperiais...

${ }^{25}$ Note-se, entretanto, que a ouvidoria de São Paulo foi criada ainda no período que a capitania estava nas mãos de um donatário.

${ }^{26}$ Indulto de perdam que S. Magde, concedeo aos moradores desta Ouvedoria Geral das Capitanas do Sul. RAMSP. Ano I, vol. I, 1934. pp. 45-46.
} 
Coroa. Com a nomeação do ouvidor, as prerrogativas de aplicação de justiça haviam sido retiradas da alçada dos donatários.

Dada a expectativa em torno das riquezas obtidas com a mineração, o ouvidor de São Paulo também recebeu o encargo de fiscalizar e ordenar a retirada de ouro das regiões sob sua jurisdição: "Vizittareis as Minas do ouro de Sam Paulo, ordenando que dellas Setirem ouro, e Se Freqüentem, eponham, emboa aRrecadaçam os direitos deminha fazenda, e mea Vizareis do Estado emque estão, e do que he nesseçario proverçe" ${ }^{27}$ Notadamente, a grande preocupação do Estado português era com o contrabando de ouro. E, nessa matéria, os ouvidores de São Paulo deveriam ter grande cuidado e atenção.

Antonio Luiz Peleja Eu El Rey vos emvio mto. Saudar, O gor. Da praça deSantos, em carta de 14 de Agosto do anno paçado, meRemeteo aCarta etresllado dadeVaça que Com esta Sevos emvia, tirada pello Provedor das Minas da vila de Pernaguá; e porque esta deVaça he nulla, emto. Mais apernunciação, meparesseo mandarvola Remeter para que hindo em Correição aVila de Parnagoá façais auto dos des Caminhos que nela Setrata, e dos impedimentos de Justiça. e tireis asmesmas testemunhas, queimando aVta. De Cada huma o Seu dito, pa. deporem Com toda aLiberdade aVerdade; e asmais testemunhas que Vos

${ }^{27}$ Três Lado do Regimto. Dos Ouvidores Gerais do Rio de Janeiro \&a. RAMSP. vol. VIII, 1935, pp. 55 - 60, p. 55. Ver também: Alvará de sua Majestade para os ouvidores de São Paulo se governarem pelo Regimento dos do Rio de Janeiro. p. 53. 
parecer, eproçedais naforma dedireito, dando Lvramto. Aos Culpados Se os houvere, escrita em Lisboa a 28 de fevero de $1703 .^{28}$

Ou seja, em relação à região que nos interessa mais de perto, Paranaguá também era reconhecida como área de exploração aurífera. De fato, as maiores incursões e consequiente povoamento do extremo sul do Brasil colonial foram movidos pela notícia das descobertas de ouro em Paranaguá. No contexto aurífero, portanto, que no ano de 1648, foi fundada a vila de Nossa Senhora do Rosário de Paranaguá. ${ }^{29}$ O povoamento dessa vila, entretanto, já vinha se formando desde pelo menos fins do século XVI, devido a uma migração espontânea de vicentinos para a região. ${ }^{30}$

A possibilidade de existir grandes riquezas na região meridional por causa da mineração fez, ainda, com que se criasse em 1660, pelo Marquês de Cascais, uma capitania autônoma, a Capitania de Paranaguá. Contudo, passados alguns anos, viram-se frustradas a descoberta de grandes minas na região. A escassez aurífera fez com que

${ }^{28}$ Carta de Sua Magde. Porq. Semanda deVaçar dos desCaminhos do ouro empó emaVila de Pernaguá. RAMSP. Ano I, vol. II, 1934. p. 68.

${ }^{29}$ Ver: BALHANA, A.; MACHADO, B. P. \& WESTPHALEN, C. M. História do Paraná. Curitiba: Grafipar, v. 1, 1969.

${ }^{30}$ Ver, dentre outros: MEQUELUSSE, Jair. A população da vila de Paranaguá no final do século XVIII. Dissertação de mestrado. Curitiba: UFPR, 1975. 
entrasse em crise aquele território, onde as vilas de Paranaguá e Curitiba passaram a basear sua subsistência em outras atividades, como a lavoura e comércio. ${ }^{31}$

As largas distâncias entre as vilas subordinadas à jurisdição da ouvidoria de São Paulo, logo obrigaram à criação de uma nova ouvidoria. Assim, em 1723, com a criação da comarca de Paranaguá, cujo termo abrangia as vilas de Cananéia, Iguape, Paranaguá, Curitiba, São Francisco e Laguna, almejava-se atender de maneira mais efetiva os anseios de suas populações por justiça, ao mesmo tempo em que tal medida significaria uma redução nas despesas: " $p$ a a Villa de Pernagoa, tenho nomeado Ouvidor geral com que fica menos trabalhoso o lugar de Ouvidor geral de São Paulo [...] 26 de Abril de 1723". ${ }^{32}$

A respeito da criação da nova ouvidoria, mais especificamente sobre os ordenados do novo ouvidor, manifestou-se desta forma o governador e capitão-general da capitania de São Paulo, D. Rodrigo César de Meneses:

${ }^{31}$ NEGRÃO, F. Memória histórica paranaense. Curitiba: Impressora Paranaense, 1934. p. 41.

${ }^{32}$ Arquivo Histórico Ultramarino (AHU). São Paulo, caixa 4, doc. 402. Provisão régia anexa à carta do governador e capitão-general da capitania de São Paulo, Rodrigo César de Meneses, para Dom João V. São Paulo, 14 de Agosto de 1724. Projeto Resgate, Inventário Mendes Gouveia. 
Como V Mag. ${ }^{\text {de }}$ foi Servido Mandar criar Novo Lugar de ouvidor geral, p. ${ }^{a}$ a V. ${ }^{a}$ de Pernagoa, ao qual Se anexando as Mais Villas da costa do mar e [Ilegivel 1 palavra.] com menos trabalho o Ouv. ${ }^{\mathrm{dr}}$ geral desta Cidade, não fazendo tanta despeza nas Correições daquellas $\mathrm{V}$. ${ }^{\text {as }}$ que dantes estavão unidas a Ouvidoria g. ${ }^{\text {al }}$ desta Cidade, Me parece Se lhe não deve acrescentar o ordenado. Mas Sim mandar Se tire do Rendimento das Câmaras, q [Il.1p.]cão na sua Com. ${ }^{\text {ca }}$, o ordenado dos quatro Centos mil [Il.1p.], q se lhe paga cuja importância pouparâ a Real faz. ${ }^{\mathrm{a}}$ e poderá ter a q [Il.1p.]acão p. ${ }^{a}$ couza mais neceSsr. ${ }^{a}$ V Mag. ${ }^{\mathrm{e}}$ Mandarâ o que for Servido.

$\mathrm{q}^{\mathrm{e}}$ a Real peSsoa de V Mag. ${ }^{\mathrm{e}}$ São Paulo 17 de Agosto de 1724

Rodrigo Cezar de Menezes ${ }^{33}$

Conforme a documentação, os ordenados do novo ouvidor deveriam ser os mesmos que dos ouvidores do Rio de Janeiro e São Paulo. Uma mercê régia dada ao primeiro ouvidor de Paranaguá assegurava o recebimento de tais valores.

Ouve S. Mgd. ${ }^{e}$ p' bem tendo consideração ao q' Se lhe reprezentou por p. $^{\text {te }}$ do d. ${ }^{o}$ B. ${ }^{\text {el }}$ An. ${ }^{\text {to }}$ Alves Lenhas Peixoto q' Se acha provido em o Lugar de Ouvidor g. ${ }^{1}$ da V. ${ }^{a}$ de Pernagua criado de novo em razão do trabalho q' ha de ter e despeza q' ha de fazer na jornada não So com a passagem $p .{ }^{a}$ o Rio de Janr. ${ }^{o}$ mas tãobem delle p. ${ }^{a}$ a d. ${ }^{a} \mathrm{~V} .{ }^{\mathrm{a}}$, e Ser justo q' por todos os respeitos se lhe arbitre o ordenado e apozentadoria q' com o d. ${ }^{\circ}$ Lugar ha de vencer pedindo o regulasse pello q' tem os Ouvidores do Rio e São Paulo e sendo visto seo requerim. ${ }^{\text {to }} \mathrm{e}$ atendendo as

${ }^{33} I d$. 
razoes q' reprezentou $\mathrm{Ha} \mathrm{S}$. Mgd. ${ }^{\mathrm{e}} \mathrm{p}^{\prime}$ bem q' o d. ${ }^{\circ}$ An. ${ }^{\text {to }}$ Alves Lenhas Peixoto vença com a d. ${ }^{\mathrm{a}}$ Ouvedoria da V. ${ }^{\mathrm{a}}$ de Pernagua criado de novo 400rs de ordenado cada anno e 40rs de apozentadoria q' he o mesmo q' Se deo ao Ouvidor de São Paulo De q' lhe foi passado Alvara a 23. de Agosto de $724 .^{34}$

Como já mencionado, a jurisdição da ouvidoria geral de Paranaguá estendia-se pelo extremo sul do Estado do Brasil. Seu primeiro ouvidor foi Antonio Álvares Lanhas Peixoto, que só chegou àquele território nos finais de $1725 .^{35}$

Alguns anos antes de sua chegada, entre fins de 1719 e meados de 1721, a freguesia de Desterro, e as vilas de Laguna, São Francisco, Curitiba e Paranaguá, haviam sido percorridas pelo ouvidor-geral de São Paulo, Rafael Pires Pardinho, que deixou suas impressões sobre as condições da vida administrativa, civil e econômica da região.

Em carta de 30 de agosto de 1721, Rafael Pires Pardinho, informava à administração central alguns aspectos das vilas de Curitiba

${ }^{34}$ Arquivo Nacional da Torre do Tombo (ANTT). Registro Geral de Mercês. Cota: Dom João V, livro 7, folha 98 .

${ }^{35}$ AHU. São Paulo, caixa 1, doc. 53. Carta do ouvidor geral da comarca de Paranaguá, Antônio Álvares Lanhas Peixoto, ao rei Dom João V. Paranaguá, 3 de janeiro de 1726. Projeto Resgate, documentos Avulsos. Segundo a documentação, Lanhas Peixoto nem mesmo queria dirigir-se a Paranaguá, chegando a solicitar sua própria prisão, por "ter demorado" a embarcar rumo àquela vila. Cf. São Paulo, caixa 4, doc. 487. Carta do ouvidor geral da comarca de Paranaguá, Antônio Álvares Lanhas Peixoto, ao rei Dom João V. Abril de 1725. Projeto Resgate, Inventário Mendes Gouveia. 
e Paranaguá, observando que deixou naquelas vilas diversos provimentos que denotariam melhor o estado que se encontravam, deste modo enviou uma cópia dos mesmos ao rei. ${ }^{36}$

Conforme Francisco Negrão, foi Rafael Pires Pardinho o responsável pela proposta de criação de mais uma ouvidoria para a capitania régia de São Paulo. ${ }^{37}$ Contudo, antes de ser efetivamente ocupada, a criação da ouvidoria geral de Paranaguá foi muito contestada pelo ouvidor de São Paulo e sucessor de Pardinho, Manoel de Mello

36 “Dous annos há, Senhor, que ando ausente da Cidade de São Paulo, e os tenho gasto em fazer corryção nestas quatro villas penultimas povoações do Estado [Laguna, São Francisco, Curitiba e Paranaguá], ou para melhor dizer em as criar, como de novo, no que entendi fazia a Vossa Magestade o maior serviço, e bem a estes povos, que vivem em tão grande distancia: porque sendo esta a primeira correyção, que nellas se fez, e ode não he fácil fazerem-se a miude, vir, e passar por ellas, em pouco tempo se não podia attender ao muito de que necessitavão, para em parte se emendarem os erros, e abusos passados, e se reparar aos futuros. E que este fosse o único fim, que nellas me demorou, se mostra bem da certeza, de que mais util me havia de ser no mesmo tempo correr a maior parte das villas da Comarca, e circunvisinhas áquella cidade, do que andar nestas ultimas pobres, e miseráveis". Carta do ouvidor-geral de São Paulo Rafael Pires Pardinho ao Rei D. João V, 30 de agosto de 1721. Em: SANTOS, Antonio Cesar de Almeida; PEREIRA, Magnus Roberto de Mello. Para o Bom Regime da República: ouvidores e câmaras municipais no Brasil colonial. Monumenta, inverno 2000, Curitiba: Aos Quatro Ventos, v. 3, n. 10, 2001, pp. 21-26. p. 26.

37 NEGRÃO, F. Genealogia Paranaense. vol. I. Curitiba : Imprensa Oficial do Paraná, 1926. p. 144. 
Godinho Manso, que reclamava da perda de receitas para a sua ouvidoria. ${ }^{38}$

Mesmo com a chegada do ouvidor Antonio Álvares Lanhas Peixoto, este permaneceu pouco tempo na ouvidoria de Paranaguá. Em 1726, recebeu ordens para tomar parte na comitiva do governador D. Rodrigo César de Menezes que se dirigia às minas de Cuiabáa ${ }^{39}$ para, entre outras determinações, efetuar a fundação da vila real do Senhor Bom Jesus do Cuiabá ${ }^{40}$. Entretanto, no pequeno espaço de tempo em que esteve à frente da comarca de Paranaguá, seguiu as atribuições inerentes a seu cargo, solicitando o regimento para sua comarca, o envio de livros para os registros de suas funções e aplicando as justiças em seu termo. ${ }^{41}$

38 AHU. São Paulo, caixa 4, doc. 429. Carta do ouvidor-geral da comarca de São Paulo, Manuel de Melo Godinho Manso, ao rei Dom João V. São Paulo, 02 de Setembro de 1724. Projeto Resgate, Inventário Mendes Gouveia.

${ }^{39}$ Aquivo do Estado de São Paulo (AESP). Caixa 73, Pasta 01, Documento 76-1-1. Carta de Antonio Álvares Lanhas Peixoto à Rodrigo César de Meneses de 11 de junho de 1726.

${ }^{40}$ A Vila Real do Senhor Bom Jesus do Cuiabá foi erigida em primeiro de janeiro de 1727; na mesma data, foi eleita a sua câmara municipal pelo ouvidor "Antonio Alvez Lanhas Peixoto, ouvidor geral da comarca de Paranaguá, sendo por ele eleitas as justiças [...]". Ata de Fundação da Vila Real de Cuiabá. In: LEITE, L. P. P. Vilas e fronteiras coloniais. Cuiabá: [Edição do autor], s./d., p. 52.

${ }^{41}$ AHU. São Paulo, caixa 1, doc. 57. Certidão passada pelo escrivão da ouvidoria geral da comarca de Paranaguá, Luís Henriques, a respeito do fato do ouvidor daquela recém-criada comarca, Antônio Álvares Lanhas Peixoto ter enviado carta solicitando 
No que diz respeito à população das vilas de Curitiba e Paranaguá, em 1721, o ouvidor de São Paulo Rafael Pires Pardinho referenciava "1400 pessoas de confissão" para a vila de Curitiba e "2000 pessoas" para a vila de Paranaguá. ${ }^{42}$ Ou seja, Pardinho utilizouse dos róis de confessados para informar estes números, excluindo a população infantil, escravos e índios administrados.

Para a primeira metade do século XVIII, os dados populacionais são fragmentados e pontuais. Contudo, para o último quartel daquele século o Estado português passou a solicitar que os governadores de seus territórios "efetuassem recenseamentos periódicos das populações existentes nas regiões subordinadas a eles". ${ }^{43}$

Assim, para a Capitania de São Paulo, a aplicação dessa nova política ficou a cargo, entre 1765 e 1775, de D. Luís Antonio de Souza

os papéis concernentes à sua jurisdição à comarca de São Paulo e ainda não ter obtido resposta. Paranaguá, 29 de abril de 1726. Projeto Resgate, documentos Avulsos. . São Paulo, caixa 1, doc. 58. Carta do ouvidor geral da comarca de Paranaguá, Antônio Álvares Lanhas Peixoto, ao rei Dom João V. Paranaguá, 30 de abril de 1726. Projeto Resgate, documentos Avulsos.

${ }^{42}$ Carta do ouvidor-geral de São Paulo... In: Monumenta, Op. cit., p. 22 e p. 24.

${ }^{43}$ WAGNER, A. P. O Império Ultramarino Português e o recenseamento de seus súditos na segunda metade do século XVIII. In: VI ${ }^{\mathbf{a}}$ Jornada Setecentista: Conferências e Comunicações. Curitiba, Aos Quatro Ventos, CEDOPE, 2006. p. 120. 
Botelho Mourão, o Morgado de Mateus. ${ }^{44}$ Neste período também ocorreu uma inflexão no que diz respeito a expansão territorial do Brasil meridional, devido às conseqüências da assinatura do Tratado de Madri (1750), a partir do qual espanhóis e portugueses procuraram definir as fronteiras de seus territórios americanos. ${ }^{45}$

A propósito dos recenseamentos feitos na capitania de São Paulo, o Morgado de Mateus ordenou uma contagem sistemática da população por meio de listas nominativas. Estas listas, organizadas em companhias de ordenanças, tinham por objetivo "conhecer a composição da população visando a uma melhor arrecadação de impostos e à identificação das potencialidades militares da população em função das disputas de fronteira com a Espanha". ${ }^{46}$ Ao seguir as determinações da administração central, o governador da capitania de São Paulo promoveu o recenseamento da população das vilas situadas em seu território.

${ }^{44}$ Sobre o Morgado de Mateus ver: BELLOTTO, H. L. Autoridade e conflito no Brasil colonial: o governo do Morgado de Mateus em São Paulo (1765-1775). São Paulo: Conselho Estadual de Artes e Ciências Humanas, 1979.

${ }^{45}$ Sobre a expansão territorial do Brasil meridional, ver, entre outros: SANTOS, A. C. de A.; JOÃO, M. T. D. Política pombalina e a expansão territorial do Brasil meridional. In: XXV Reunião Anual da SBPH, 2005, Rio de Janeiro. Anais da XXV Reunião da SBPH. Rio de Janeiro: SBPH, 2005. v. 1. p. 165-170.

${ }^{46}$ STANCZYK FILHO, Milton. À luz do cabedal: acumular e transmitir bens nos sertões de Curitiba (1695-1805). Dissertação de Mestrado. Departamento de História. Universidade Federal do Paraná, Curitiba, 2005. p. 43. 
[...] cada vila foi reorganizada em Companhias de Ordenanças com base na quantidade das populações. Curitiba foi dividida em cinco Companhias: primeira e segunda Companhias da vila de Curitiba, a freguesia do Patrocínio de São José (terceira Companhia ); a freguesia de Santo Antonio da Lapa (quarta Companhia) e a freguesia de Sant'Ana do Yapó (quinta Companhia). Os primeiros censos consideraram apenas a população livre. Entretanto, a partir da década de 1770 , todos os habitantes foram incluídos nas listas, à exceção dos indígenas, cuja maioria escapava ao controle das autoridades portuguesas. 47

Para se ter uma ideia do contingente populacional sob as quais deveriam incidir à ação dos ouvidores da comarca de Paranaguá, para o ano de 1798, Horacio Gutiérrez informa que os municípios de Antonina, Guaratuba, Paranaguá, Castro e Curitiba tinham uma população de cerca de 21.000 pessoas. ${ }^{48}$ No mesmo ano, conforme dados de Agnaldo Valentin, a população da vila de Iguape, entre livres e cativos, era de 4.291 indivíduos. $^{49}$

${ }^{47} I d$.

${ }^{48}$ GUTIÉRREZ, Horacio. Donos de terras e escravos no Paraná: padrões e hierarquias nas primeiras décadas do século XIX. História (São Paulo), v. 25, p. 100-122, 2006. p.102. Disponível em: http://www.scielo.br/pdf/his/v25n1/a05v25n1.pdf Acesso em 29/dez/2006.

${ }^{49}$ VALENTIN, Agnaldo. Comércio marítimo de abastecimento: o porto de Iguape (SP), 1798-1880. In: CONGRESSO BRASILEIRO DE HISTÓRIA ECONÔMICA, 5., 2003, Caxambu/MG. Atas do V Congresso Brasileiro de História Econômica. 
Mesmo para as décadas precedentes pode-se identificar o crescimento populacional das vilas pertencentes à comarca de Paranaguá, principalmente as vilas de Curitiba e Paranaguá.

Entre 1776 e 1785, Maria Ignes Mancini De Boni indica um crescimento de $91 \%$ da população da vila de Curitiba, resultado do aumento do número de escravos e do acréscimo territorial da vila, com o surgimento de novos bairros. ${ }^{50}$ Assim, para 1776, havia 2.098 indivíduos livres e 407 escravos, totalizando 2.505 moradores na vila de Curitiba; em 1785 esse total passou para 4.566, sendo 3.517 livres e 1.049 escravos. A vila de Paranaguá, por sua vez, em 1786 contava com 3.595 livres e 1.078 escravos, somando 4.673 indivíduos. ${ }^{51}$

Disponível em: http://www.abphe.org.br/congresso2003/Textos/Abphe_2003_73.pdf Acesso em 13/jan/2007.

${ }^{50}$ DE BONI, Maria Ignez Mancini. A população da Vila de Curitiba segundo as listas nominativas de habitantes, 1765-1785. Dissertação de Mestrado. Departamento de História. Universidade Federal do Paraná. Curitiba, 1974. p. 50. Note-se que a população da vila não corresponde necessariamente a população do termo do município.

${ }^{51}$ AESP. Lista Nominativa de Habitantes da vila de Paranaguá, 1786. Mapa geral de habitantes presente no Acervo do Centro de Documentação e Pesquisa de História dos Domínios Portugueses, séculos XV-XIX - CEDOPE. Departamento de História da UFPR. 


\section{Políticas Administrativas}

Dos 89 anos analisados da ouvidoria de Paranaguá (1723-1812), o extenso território de sua comarca, bem como o contingente populacional a que nos referimos acima, esteve sob a jurisdição de 14 oficiais. Sendo que é importante destacar que o ouvidor Gaspar da Rocha Pereira não fora nomeado pelo Desembargo do Paço, instituição que administrava tais nomeações, mas sim pelo governo geral do Estado do Brasil. Também se deve observar o caso de Joaquim de Amorim e Castro, oficial que ocupou o cargo de desembargadorsindicante em Paranaguá, contrariamente à opinião Antonio Vieira dos Santos, que o identificou como ouvidor da comarca. ${ }^{52}$ Amorim e Castro foi o oficial destacado para promover a devassa do ouvidor João Batista dos Guimarães Peixoto, no intuito de averiguar sua conduta, bem como os motivos que induziram o governador e capitão general da Capitania de São Paulo, Antonio Manoel de Melo Castro e Mendonça, a suspender o ouvidor de seus ofícios, em $1802 .{ }^{53}$

Sobre os ouvidores de Paranaguá, foi possível identificar que, dois deles haviam exercido o cargo de juiz de fora no reino por duas

52 SANTOS, Antonio Vieira dos. Memória histórica de Paranaguá: Volume II. Curitiba: Vicentina, 2001. p. 28.

${ }^{53}$ AESP. Caixa 76, Pasta: 02, Documento 76-2-9. 
vezes. Também identificamos que seis ouvidores haviam sido juízes de fora apenas uma vez no reino, sendo que um deles atuou concomitantemente como juiz de fora em duas vilas, além de também ter exercido o cargo de advogado na corte, e outro que havia possuído o cargo de juiz de fora tanto no reino como no Estado do Brasil. Dos demais, um ocupou o cargo de advogado no reino e de juiz de fora no Estado do Brasil. Não foi possível determinar as ocupações anteriores de cinco indivíduos. Nesses casos, existe a possibilidade do cargo de ouvidor ser a primeira nomeação; contudo, observando os anos em que foram homologados os pedidos de magistraturas no Desembargo do Paço, acredita-se na hipótese desses últimos terem desenvolvido outras atividades antes de serem nomeados ouvidores em Paranaguá. Essa situação, parece confirmar os resultados encontrados por José Subtil e Maria Goretti Soares, que apontam que os ouvidores designados para o Brasil eram, em sua maioria, letrados com experiência no ofício. ${ }^{54}$

\footnotetext{
${ }^{54}$ SUBTIL, J.; SOARES, M. G., Op. cit. "Cerca de 55\% foram juízes de fora e 3\% exerceram outros cargos no Reino, $8 \%$ foram juízes de fora no Brasil e 3\% tiveram provimento de ofícios nas Ilhas. Apenas $31 \%$ foram providos pela primeira vez. Quase todos são naturais do Reino, com exceção para meia dúzia de casos, mas a taxa de retorno destes magistrados [ao Reino] é, aproximadamente, de $25 \%$, provavelmente até menos, dado que alguns ouvidores, promovidos a desembargadores na Relação do Porto, o terão sido como aposentados. Estes indicadores apontam para uma forte emigração de elites letradas para o Brasil, agraciadas com várias mercês régias. Uma delas é a promoção a desembargador, na maioria parte dos casos, nos tribunais do
} 
Sob a perspectiva da dinâmica das nomeações, é possível apontarmos que o reinado de Dona Maria I (com a regência de príncipe dom João) é aquele em que encontramos o maior número de nomeações de ouvidores para a comarca de Paranaguá, no total de seis, não obstante o largo período de tempo compreendido entre os anos de 17771812. Para os dois reinados anteriores constata-se uma grande discrepância, pois, nos 27 anos do reinado de Dom José I foram nomeados apenas dois ouvidores, enquanto que no reinado de dom João $\mathrm{V}$, para o período compreendido entre os anos de instalação da comarca (1723) e 1750, foram feitas cinco nomeações. ${ }^{55}$ Desta forma, é possível observar que o ritmo de nomeações feitas pela administração central do Estado português não acompanhava os três anos de mandato dos ouvidores no exercício de seus cargos.

Reino, particularmente a Relação do Porto e a Casa da Suplicação, (cerca de um quarto dos providos). Segue-se, depois, a Relação da Baía e Rio de Janeiro (7\%). Há até dois casos de nomeação para desembargadores do Desembargo do Paço".

${ }^{55}$ Como o ouvidor Gaspar da Rocha Pereira não foi nomeado pelo Desembargo do Paço, não foi contabilizado nos dados. Para os dados informados, ver: ANTT. Registro Geral de Mercês. Cota: Dom João V, Livro 7, Folha 98; Livro 7, Folha 177; Livro 13, Folha 263; Livro 29, Folha 33; Chancelaria de D. João V, Livro 115, Folha 378v; Registro Geral de Mercês. Cota: Dom José I, Livro 8, Folha 389; Livro 25, Folha 187; Registro Geral de Mercês. Cota: Dona Maria I, Livro 15, Folha 6; Livro 25, Folha 9; Livro 14, Folha 179; Chancelaria de D. Maria I, Livro 67, Folha 257; Livro 71, 178. 
Para que a comarca não ficasse "abandonada", dois foram os artifícios utilizados na comarca de Paranaguá. O primeiro, deixava-se de lado a necessidade de preparo jurídico profissional, e apoiando-se nos regimentos dos ouvidores, o juiz ordinário mais velho ocupava o cargo de ouvidor até outro oficial ser destacado para ocupar a função.

Sendo doente O ouvidor Letrado, posto por min, ou inpedido de maneira que não possa Servir, Servirá o Juis mais Velho de Ouvidor, o qual SerVirá durante Seu inpedimento; e falesendo, ou Sendo Inpedido de Sorte que haja de durar mais de Seis mezes Proverá o governador Geral do Estado apeçoa que mais Sufficiente paresser pa. o ditto Cargo, pello Conçelho VLtra Marino pera eu mandar o que ouver por quanto durar o ditto Inpedimento $[\ldots]{ }^{56}$

O segundo artifício, mais provável, seria a manutenção do ouvidor no cargo até ser nomeado outro oficial para a sua sucessão. Aliás, esta disposição constava, no geral, nas cartas de nomeação: "Servir por tempo de tres annos E o mais q' decorrer emq. ${ }^{\text {to }}$ Eu não mandar o contr. ${ }^{0 "} .57$

Desses dados apresentados é possível perceber que existia uma política determinada para a ouvidoria de Paranaguá. De um modo geral,

${ }^{56}$ Três Lado do Regimto. Dos Ouvidores Gerais do Rio de Janeiro \&a. RAMSP. vol. VIII, 1935, pp. 55-60, p. 59.

${ }^{57}$ ANTT. Chancelaria de Dona Maria I. Livro 34, folha 217. 
pode-se notar que os indivíduos eram nomeados após uma experiência no trato jurídico-administrativo. Além do mais, em sua maioria, eram indivíduos naturais do reino, especialmente quando referido a um período anterior a 1780. Tinham, na ocasião que recebiam suas mercês, aproximadamente 30 anos de idade e eram solteiros.

Esses ouvidores, encarregados de promover a justiça régia na América portuguesa, configuravam-se como um grupo de oficiais letrados e, no prisma do Estado português, eram capazes de desenvolver suas atividades na América. Porém, o que se busca avançar em nova pesquisa é verificar como as estratégias individuais desses indivíduos concorreram paralelamente as suas ações administrativas.

\section{Referências}

ALENCASTRO, L. F. O trato dos viventes: formação do Brasil no Atlântico sul. São Paulo: Companhia das Letras, 2000.

Arquivo do Estado de São Paulo (AESP). Caixa 73, Pasta 01, Documento 76-1-1. Carta de Antonio Álvares Lanhas Peixoto à Rodrigo César de Meneses de 11 de junho de 1726.

Arquivo do Estado de São Paulo. Caixa 76, Pasta: 02, Documento 762-9. 
Arquivo do Estado de São Paulo. Lista Nominativa de Habitantes da vila de Paranaguá, 1786. Mapa geral de habitantes presente no Acervo do Centro de Documentação e Pesquisa de História dos Domínios Portugueses, séculos XV-XIX - CEDOPE. Departamento de História da UFPR.

Arquivo Histórico Ultramarino (AHU). São Paulo, caixa 1, doc. 57. Certidão passada pelo escrivão da ouvidoria geral da comarca de Paranaguá, Luís Henriques, a respeito do fato do ouvidor daquela recém-criada comarca, Antônio Álvares Lanhas Peixoto ter enviado carta solicitando os papéis concernentes à sua jurisdição à comarca de São Paulo e ainda não ter obtido resposta. Paranaguá, 29 de abril de 1726. Projeto Resgate, documentos Avulsos.

Arquivo Histórico Ultramarino (AHU). São Paulo, caixa 4, doc. 402. Provisão régia anexa à carta do governador e capitão-general da capitania de São Paulo, Rodrigo César de Meneses, para Dom João V. São Paulo, 14 de Agosto de 1724. Projeto Resgate, Inventário Mendes Gouveia.

Arquivo Histórico Ultramarino (AHU). São Paulo, caixa 4, doc. 429. Carta do ouvidor-geral da comarca de São Paulo, Manuel de Melo Godinho Manso, ao rei Dom João V. São Paulo, 02 de Setembro de 1724. Projeto Resgate, Inventário Mendes Gouveia.

Arquivo Nacional da Torre do Tombo (ANTT). Registro Geral de Mercês. Cota: Dom João V, livro 7, folha 98. 
Revista Vernáculo, $n^{\circ} 29,1^{\circ}$ sem/2012

Arquivo Nacional da Torre do Tombo (ANTT). São Paulo, caixa 1, doc. 53. Carta do ouvidor geral da comarca de Paranaguá, Antônio Álvares Lanhas Peixoto, ao rei Dom João V. Paranaguá, 3 de janeiro de 1726. Projeto Resgate, documentos Avulsos.

BALHANA, A.; MACHADO, B. P. \& WESTPHALEN, C. M. História do Paraná. Curitiba: Grafipar, v. 1, 1969.

BellotTo, H. L. Autoridade e conflito no Brasil colonial: o governo do Morgado de Mateus em São Paulo (1765-1775). São Paulo: Conselho Estadual de Artes e Ciências Humanas, 1979.

BICALHO, M. F.; FERLINI, V. L. A. (Orgs.). Modos de governar: ideias e práticas políticas no império português - Séculos XVI-XIX. São Paulo: Alameda, 2005.

BOXER, C. O império marítimo português 1415-1825. São Paulo: Companhia das Letras, 2002.

BOXER, C. R. A idade de ouro do Brasil. Dores de crescimento de uma sociedade colonial. São Paulo: Nacional, 1963.

CUNHA, M. S. da. Governo e governantes do Império português do Atlântico (século XVII). Em: BICALHO, M. F.; FERLINI, V. L. A. (Orgs.). Modos de governar: ideias e práticas políticas no império português - Séculos XVI-XIX. São Paulo: Alameda, 2005.

DE BONI, Maria Ignez Mancini. A população da Vila de Curitiba segundo as listas nominativas de habitantes, 1765-1785. Dissertação 
de Mestrado. Departamento de História. Universidade Federal do Paraná. Curitiba, 1974.

FRAGOSO, J.; BICALHO, M. F.; GOUVÊA, M. de F. (Org.). O antigo regime nos trópicos: a dinâmica imperial portuguesa (séculos XVI-XVIII). Rio de Janeiro: Civilização Brasileira, 2001.

FURTADO, J. F. (Org.). Diálogos oceânicos: Minas Gerais e as novas abordagens para uma história do Império Ultramarino Português. Belo Horizonte: UFMG, 2001.

GOUVÊA, M. de F. Conexões imperiais: oficiais régios no Brasil e Angola (c. 1680-1730). CUNHA, M. S. da. Governo e governantes do Império português do Atlântico (século XVII). Em: BICALHO, M. F.; FERLINI, V. L. A. (Orgs.). Modos de governar: ideias e práticas políticas no império português - Séculos XVI-XIX. São Paulo: Alameda, 2005.

GOUVÊA, M. de F. Poder político e administração na formação do complexo atlântico português (1645-1808). In: FRAGOSO, J.; BICALHO, M. F.; GOUVÊA, M. de F. (Org.). O antigo regime nos trópicos: a dinâmica imperial portuguesa (séculos XVI-XVIII). Rio de Janeiro: Civilização Brasileira, 2001. pp. 287-315, p. 288.

GOUVÊA, Maria de Fátima, FRAZÃO, Gabriel Almeida \& SANTOS, Marília Nogueira dos. "Redes de Poder e Conhecimento na Governação do Império Português, 1688-1735". Em: TOPOI, Revista de História do 
Revista Vernáculo, $n^{\circ} 29,1^{\circ}$ sem/2012

Programa de Pós-graduação em História Social da UFRJ v. 5. (8). jun 2004. 2004.

GUTIÉRREZ, Horacio. Donos de terras e escravos no Paraná: padrões e hierarquias nas primeiras décadas do século XIX. História (São Paulo), v. 25, p. 100-122, 2006. p.102. Disponível em: http://www.scielo.br/pdf/his/v25n1/a05v25n1.pdf Acesso em 29/dez/2006.

HESPANHA, A. M. As Estruturas Políticas em Portugal na Época Moderna. Em: TENGARRINHA, José (Org.). História de Portugal. 2. ed. São Paulo: UNESP, 2001. pp. 117-181.

HESPANHA, A. M. Justiça e administração entre o Antigo Regime e a Revolução. Em: ___ Justiça e litigiosidade: história e prospectiva. Lisboa: Fundação Calouste Gulbenkian, 1993.

HESPANHA, Antonio Manuel. Cultura Jurídica Européia. Síntese de um milénio. $3^{\text {a }}$ Ed. Mira-Sintra: Europa-América, 2003.

LACERDA, Arthur. As ouvidorias do Brasil colônia. Curitiba: Juruá, 2000.

MEQUELUSSE, Jair. A população da vila de Paranaguá no final do século XVIII. Dissertação de mestrado. Curitiba: UFPR, 1975.

NEGRÃO, F. Genealogia Paranaense. vol. I. Curitiba : Imprensa Oficial do Paraná, 1926. 
NEGRÃO, F. Memória histórica paranaense. Curitiba: Impressora Paranaense, 1934. p. 41.

PEGORARO, J. W. A justiça régia e as estratégias de controle da população da "América portuguesa" (Séc. XVIII). Atas do I Congresso Internacional de História: Território, Culturas e Poder, Braga, Instituto de Ciências Sociais da Universidade do Minho, 5 a 7 de dezembro de 2005.

PEGORARO, J. W. Ouvidores régios em Paranaguá: uma discussão sobre a centralização jurídico-administrativa na América Portuguesa (1723-1812). Em: DORÉ, A: SANTOS, A.C. de A. (Orgs.) Temas setecentistas: governos e populações no Império Português. Curitiba: UFPR-SCHLA/Fundação Araucária, 2008.

Revista do Arquivo Municipal de São Paulo (RAMSP). Ano I, vol. I, 1934. pp. 45-46. Indulto de perdam que S. Magde, concedeo aos moradores desta Ouvedoria Geral das Capitanas do Sul.

Revista do Arquivo Municipal de São Paulo (RAMSP). Ano I, vol. II, 1934. p. 68. Carta de Sua Magde. Porq. Semanda deVaçar dos desCaminhos do ouro empó emaVila de Pernaguá.

Revista do Arquivo Municipal de São Paulo (RAMSP). Ano I, vol. I, 1934. pp. 49-50. Termo que fizerão entre Sy os ouvidores gerais o primeiro que foi desta ouvidoria, e o Ouvidor geral que no tempo hera em o Ryo de Janeiro em o qual se declarou as Vilas pertencentes a esta ouvidoria. 
Revista do Arquivo Municipal de São Paulo (RAMSP). vol. VIII, 1935, pp. 55 - 60. Três Lado do Regimto. Dos Ouvidores Gerais do Rio de Janeiro \&a.

SANTOS, A. C. de A. Para viverem juntos em povoações bem estabelecidas: um estudo sobre a política urbanística pombalina. Curitiba, 1999. Tese (Doutorado em História). Universidade Federal do Paraná.

SANTOS, A. C. de A.; JOÃO, M. T. D. Política pombalina e a expansão territorial do Brasil meridional. In: XXV Reunião Anual da SBPH, 2005, Rio de Janeiro. Anais da XXV Reunião da SBPH. Rio de Janeiro: SBPH, 2005. v. 1. p. 165-170.

SANTOS, Antonio Vieira dos. Memória histórica de Paranaguá: Volume II. Curitiba: Vicentina, 2001.

SOUZA, L. de M. Desclassificados do Ouro: a pobreza mineira no século XVIII. Rio de Janeiro: Edições Graal, 2004.

SOUZA, L. de M. e. O sol e a sombra: política e administração na América portuguesa do século XVIII. São Paulo: Companhia das Letras, 2006.

STANCZYK FILHO, Milton. À luz do cabedal: acumular e transmitir bens nos sertões de Curitiba (1695-1805). Dissertação de Mestrado. Departamento de História. Universidade Federal do Paraná, Curitiba, 2005. 
Revista Vernáculo, $n^{\circ} 29,1^{\circ}$ sem/2012

SUBTIL, J. Os Ministros do rei no poder local, ilhas e ultramar (17721826). Penélope, $\mathrm{n}^{\circ}$ 27, 2002, pp. 37-58.

SUBTIL, José Manuel Louzada Lopes. Actores, territórios e redes de poder, entre o antigo regime e o liberalismo. Curitiba: Juruá, 2011.

VAINFAS, R. Dicionário do Brasil Colonial. São Paulo: Companhia das Letras, 2003.

VALENTIN, Agnaldo. Comércio marítimo de abastecimento: o porto de Iguape (SP), 1798-1880. In: CONGRESSO BRASILEIRO DE HISTÓRIA ECONÔMICA, 5., 2003, Caxambu/MG. Atas do V Congresso Brasileiro de História Econômica. Disponível em: http://www.abphe.org.br/congresso2003/Textos/Abphe_2003_73.pdf Acesso em 13/jan/2007.

WAGNER, A. P. O Império Ultramarino Português e o recenseamento de seus súditos na segunda metade do século XVIII. In: VI ${ }^{a}$ Jornada Setecentista: Conferências e Comunicações. Curitiba, Aos Quatro Ventos, CEDOPE, 2006.

WEHLING, A. e WEHLING, M. J. Direito e justiça no Brasil colonial: o Tribunal da Relação do Rio de Janeiro (1751-1808). Rio de Janeiro: Renovar, 2004. p. 29. 